\title{
Drivers and Outcomes of Green IS Adoption in Small and Medium-Sized Enterprises
}

\author{
Alenka Baggia *, Matjaž Maletič, Anja Žnidaršič and Alenka Brezavšček \\ Faculty of Organizational Sciences, University of Maribor, 4000 Kranj, Slovenia; matjaz.maletic@um.si (M.M.); \\ anja.znidarsic@um.si (A.Ž.); alenka.brezavscek@um.si (A.B.) \\ * Correspondence: alenka.baggia@um.si; Tel.: +386-4-2374-246
}

Received: 11 February 2019; Accepted: 9 March 2019; Published: 15 March 2019

check for updates

\begin{abstract}
Using the Belief Action Outcome (BAO) framework as a theoretical basis, this study investigates the mechanisms that link organizational beliefs about environmental sustainability with Green information system (IS) actions that are undertaken and, hence, the organizational benefits accruing from these actions. Survey data were collected from 156 small and medium-sized enterprises (SMEs) and analyzed using Partial Least Squares Structural Equation Modeling (PLS-SEM). The results support the notion that Green IS endeavors lead to increased organizational benefits. External pressures from stakeholders and employees' attitudes to environmental sustainability affect the organizational attitude to Green IS. The attitude to Green IS is further translated into the organization's strategy and corresponding Green IS actions, resulting in organizational benefits. This study's main contribution lies in establishing a link between personal attitudes, institutional mechanisms, internal environmental/sustainability initiatives, and performance implications. Green IS adoption was empirically validated considering the SME context.
\end{abstract}

Keywords: green information systems; small and medium enterprises (SMEs); sustainable development; organizational benefits

\section{Introduction}

In recent years, several environmental and sustainability studies have suggested that smart use of information technology (IT) and information systems (IS) can substantially help green the planet [1,2]. Since organizations are increasingly recognizing environmental sustainability as an urgent problem, they might adopt a range of different 'Green' practices to enhance the efficiency of their business processes. According to Loeser [3], 'Green' refers to technologies and/or processes that are environmentally friendly and have a smaller negative impact on the natural environment than conventional ones.

During the past decade, the role of smart use of IT/IS in contributing to environmentally responsible human activity has been widely discussed in the literature, whereas the terms Green IT and Green IS have often been used interchangeably, synonymously, and/or without acknowledging the differences [4]. Some authors try to clarify the similarities and differences of these two terms [3,5-7]. Among others, Loeser [3] unambiguously distinguishes the scopes of Green IT and Green IS, describing the concepts as follows:

- The Green IT concept refers to measures and initiatives that lower the negative environmental impact of manufacturing, operations, and the disposal of IT equipment and infrastructure.

- The Green IS concept refers to practices which determine the investment in, deployment, use, and management of IS in order to minimize the negative environmental impacts of IS, business operations, and IS-enabled products and services. 
This study addresses the concept of Green IS, which Recker [8] defines as any kind of IS that assists individuals and organizations in making environmentally sustainable decisions and establishing environmentally sustainable work practices rather than environmentally unsustainable ones. This definition is consistent with an older one by Watson et al. [2] who defined Green IS as the design and implementation of IS that contribute to sustainable business processes. A similar topic, called "IS for environmental sustainability", was also presented by Melville [1] who focused on IS-enabled organizational practices and processes that improve environmental and economic performance.

The primary focus of Green IS initiatives is on designing and implementing systems to support environmental management processes [2]. Loeser et al. [9] understand Green IS initiatives as a wide range of IS-related environmental actions, including the formulation of Green IS strategies, which should be translated into sustainability actions through different Green IS practices. Green IS practices can be classified into three categories-Green IS practice with a focus on pollution prevention; Green IS practice with a focus on product stewardship, and Green IS practice with a focus on sustainable development [10].

The introduction of Green IS initiatives into an organization can bring many positive outcomes. For example, Loeser et al. [9] reported that Green IS initiatives can:

- reduce costs by increasing the resource efficiency of IT infrastructure resources [11,12] and organization-wide business processes [2];

- enhance corporate reputation by shrinking the organization's environmental footprint while providing tools for tracking and reporting environmental performance [13,14]; and

- facilitate and improve organizational capabilities for green product and process innovations, which can result in long-term organizational advantages [15-18].

Due to the substantial possible benefits of applying Green IS initiatives, this area has attracted the attention of many authors. However, an in-depth literature review (see Section 2) reveals that the implementation of Green IS by small and medium-sized enterprises (SMEs) has not been researched sufficiently, and represents a deficiency that needs to be rectified. SMEs make up between $95 \%-99 \%$ of private businesses in the world, and $99 \%$ of all businesses in the EU [19]. They employ $60 \%-70 \%$ of the workforce in most countries and on average generate $50 \%$ to $60 \%$ of value added [20]. Therefore, the attitude of SME managers to Green IS initiatives is an important issue that calls for deeper reflection. Namely, SMEs account for a large share of world pollution and thus reducing the environmental impact of SMEs in both manufacturing and services is a key factor in successfully greening the economy [19].

This paper aims to investigate the adoption of Green IS in SMEs from the viewpoint of enterprise management. Further, this paper seeks to analyze how SME managers perceive the impact of adopting Green IS on SMEs' benefits. For this purpose, a conceptual model was developed and tested in an empirical study carried out among Slovenian SMEs. Like Gholami et al. [21] and Loeser et al. [9], the model is based on the Belief Action Outcome (BAO) framework developed by Melville [1]. Namely, the BAO framework is established as the most suitable theoretical framework for integrating the antecedents of Green IS adoption with the consequences of such adoption [9,21]. To examine relationships among the model components, Partial Least Squares Structural Equation Modeling (PLS-SEM) is performed. The results are then presented and discussed.

The remainder of the paper is structured as follows. First, the results of a relevant literature review are outlined and the theoretical background of the BAO framework briefly described. Moreover, the research model and the proposed hypotheses are developed. The methodology of our empirical study is then explained and the results are given and discussed. The conclusions are outlined by means of research implications, the study's limitations, and future research recommendations. 


\subsection{Literature Review}

To clarify our study's framework, a deeper overview of the Green IT/IS literature must be examined. A comprehensive and systematic literature review in the domain of Green IT/IS is provided by several authors $[3,5,7,22,23]$. The results show the majority of studies consider the challenges related to Green IT [6,24-28] or a combination of Green IT/IS [3,29-32], while a small share of them strictly addresses the Green IS concept [33-36].

Among easily accessed Green IT/IS literature, we found that only a few papers examine the motivations and/or analyze the outcomes of Green IS adoption. Wati and Koo [37] analyzed the predictors of Green IT/IS adoption behavior and established its foundation from a motivational perspective, while Bokolo [22] addressed Green IS integration in an IT-based organization (e.g., IBM, Dell, Google, Yahoo, Microsoft, and others). The study by Gholami et al. [21] is also very valuable since it studies senior managers' perception of Green IS adoption and environmental performance. The authors presented the results of a field survey of Malaysian businesses (in which 405 senior managers collaborated; $64.2 \%$ from SMEs and $35.8 \%$ from large firms).

Several theories and models have been formulated to help understand the factors and forces that influence organizational Green IT/IS initiatives. Dalvi-Esfahani and Rahman [38] divided them into organization- and individual-level theories. According to reviews provided in [6,38-40], one may state that studies in the domain of Green IS initiatives applied both organization- and individual-level theories, although organization-level theories are more prevalent.

Applications of individual-level theories can be found in [38] where Norm Activation Theory is applied, or in [41] where the Extended Model of Goal-Directed Behavior is used. Among organization-level theories, we can most frequently find applications of Institutional Theory (e.g., [42]), Theory of Planned Behavior (e.g., [43]), Resource-Based Theory (e.g., [44]), Transaction Cost Theory (e.g., [45]), and Topology of Legitimacy (e.g., [46]). Most organization-level theories are valuable for assisting understanding of the antecedents to Green IS adoption but are less useful for explaining the outcome of Green IS adoption [21]. Therefore, the BAO framework proposed by Melville [1] proves to be very useful as it integrates both the organizational and the individual levels [38], and can clarify the antecedents as well as the benefits of Green IS initiatives [21].

Further, the literature review also showed that many authors combined more than one theory and/or framework. For example, Lei and Ngai [47] combined Institutional Theory and Organizational Information Processing Theory, while Nedbal et al. [45] integrated the Technology-OrganizationEnvironment (TOE) framework with the Diffusion of Innovation (DOI) and Theory and Process Virtualization Theory (PVT). In addition, Wati and Koo [37] combined Self-Determination Theory with the Technology Acceptance Model (TAM).

Of recently published literature (i.e., since our empirical research was performed), we should not overlook the excellent study by Loeser et al. [9] which, similarly to Gholami et al. [21], arises from the BAO framework. The study offers the results of cross-sectional global research which analyzed the orientation, strategy, practices, and benefits of Green IS initiatives in general (118 senior-level IT executives collaborated from large organizations with more than 250 up to more than 100,000 employees from highly developed countries from North America, Europe, and the Asia-Pacific region).

Loeser et al. [9] place the empirical research studies in two categories: abstract and substantive. Abstract-level studies investigate factors that influence the adoption of any type of Green IS, while substantive-level studies conceptualize the requirements for some types of Green IS, or examine particular systems for specific environmental challenges or organizational initiatives. The analysis by Loeser et al. [9] reveals that most research studies in the area of Green IS are substantive in nature. Although both types of studies are important, the substantive-level ones suffer from certain limitations: (a) they develop models that pertain only to specific cases and are hence limited in providing insights into the benefits of Green IS generally; (b) many of them are conceptual or analytical studies and do not evaluate the consequences of Green IS adoption. It is also established that the majority of research 
articles published in the Green IS domain are conceptual, as opposed to impact studies that analyze organization-level outcomes empirically ([48] as cited in [9]).

Moreover, we investigated the literature on sustainability initiatives in SMEs. We found several studies addressing the general green practices for improving SME business in a sustainable way (e.g., [49-51], while Álvarez Jaramillo et al. [52] analyzed the barriers faced by SMEs when implementing initiatives for sustainable development. Many studies investigate the importance, drivers, or barriers to environmental, green, or sustainable SMEs' innovation in a specific environment (e.g., the food and beverage sector [53]; French SMEs [54]; European SMEs [55]; Malaysia SMEs [56-58]. Moreover, Kraus et al. [59] showed that a focus on environmental sustainability can build the foundation for a path to social performance in SMEs. The authors showed that networking and communicating with companies in similar or the same industries can be a crucial factor to success of a sustainable SME. Given the sustainable entrepreneurship orientation perspectives, several important insights concerning the factors that stimulate responsible managerial practices are provided by study of Kraus et al. [60]. We also found a few papers which examined the drivers of Green IT adoption in SMEs [46,61-64]. In addition, Foogooa and Dookhitram [65] proposed a useful Green IT maturity assessment tool for SMEs. However, we were unable to find any paper concerning Green IS adoption and/or the outcomes of Green IS evaluation in the SME environment.

The literature review allows us to conclude the following:

- There is a lack of empirical studies analyzing the antecedents and outcomes of Green IS initiatives.

- The specific aspects of SMEs as important drivers of global sustainability are not addressed in the Green IS literature.

- The BAO framework is a theoretical framework, which (unlike other theories or frameworks) enables understanding of both the antecedents of Green IS adoption and integrates them with the outcomes of such adoption.

These statements provided the fundamental starting points for our research.

\subsection{Research Model and Hypotheses}

To analyze what motivates the adoption of Green initiatives by SMEs and to estimate the outcomes, a conceptual model was developed. The perception of SME managers was taken into account while developing the model. Since top management is shown to be one of the most effective predictors of IT adoption [6], it is expected that the managers of SMEs also play an important role in conveying the strategic importance of Green IS across the organization and in making resource allocation [21].

We built our model on the BAO framework [1]. This framework is suitable for SMEs because it links macro-level constructs (society, natural environment, regulations) with micro-level constructs (individuals, organization) to study the role of IS in environmental sustainability. The BAO framework also argues that managerial beliefs and commitments lead to organizational action, eventually producing outcomes which may be subjective (such as the fulfilment of corporate social responsibility, building a reputation, and brand equity) or objective (such as reduced energy consumption due to green IT, and the net impact on profits) [66]. A quick presentation of the BAO framework, explanations of belief and action formations as well as outcome aspects is given in [8] and [9]. In accordance with the BAO framework, developing our model consists of a definition of the belief formation, action formation, and the outcomes of implementing Green IS initiatives in SMEs.

Building on previous studies, we conceptualized the outcome construct of our model as perceived organizational benefits due to Green IS initiatives and their implementation $\left(\mathrm{H}_{8}, \mathrm{H}_{9}\right.$, and $\left.\mathrm{H}_{10}\right)$. In our opinion, the meaningful organizational benefits arising from Green IS initiatives are: lower waste and emissions [1,3,21,22], reduced energy consumption [21,22], a higher level of social responsibility [6,53], a greater level of employees' environmental awareness [5], and an improved company image [9,21].

Action formation describes how psychic states concerning Green IS initiatives translate into actions and Green IS practices. Many authors found that organization strategy is one of the 
general determinants of green innovations and green IT/IS adoption $[67,68]$. Therefore, we regard a "sustainability oriented" organization strategy as a trigger for implementing Green IS practices which support and stimulate the prevention of pollution $\left(\mathrm{H}_{7 \mathrm{a}}\right)$, product stewardship $\left(\mathrm{H}_{7 \mathrm{~b}}\right)$, and sustainable development $\left(\mathrm{H}_{7 \mathrm{c}}\right)[3,10,21,22,68]$. Green IS practices focusing on pollution prevention refer to the innovation and use of information systems (such as enterprise carbon and energy management systems) to reduce pollution generated by business operations. Green IS practices focusing on product stewardship refer to the innovation and use of IS (such as enterprise digital platforms and communication and collaboration systems) that enhance the environmental friendliness of upstream and downstream supply chains [10]. Green IS practices focusing on sustainable development refer to the innovation and use of IS that transform business operations [69].

To develop the belief formation of our conceptual model, we relied on previous studies that analyzed the organizational motivations for adopting Green IS or Green IT. Authors established that external pressures shape executives' personal beliefs and result in sustainability actions $[1,21]$. Therefore, this study incorporates institutional theory to identify main motives for adoption of Green IS. Based on these theoretical lenses, three types of pressures could be emphasized, namely coercive isomorphism, mimetic processes, and normative pressures [70]. However, we followed the approach of Chen, Boudreau, and Watson [71] who focused on two types of isomorphic pressures-mimetic and coercive pressures. The mimetic pressures (i.e., organizations will follow leading organizations that have already taken up Green IS initiatives) are important, since they drive organizations to adopt Green IS practices due to the positive outcomes shown by other organizations' Green IS practices [10]. It could also be argued that when organizations are faced with high level of environmental uncertainty, they may mimic the action of an organization they deem as being legitimate [70,72]. Hence, this study advocates that pressures from competitors and other stakeholders influence the adoption and diffusion of Green IS by SMEs. Furthermore, the coercive pressures (i.e., externally codified rules, norms, or laws that give legitimacy to business practices) have a significant impact on sustainable development as concerns SMEs [73]. Deng and Ji [6] reported that regulations, environmental laws as well as demands from key stakeholders require organizations to operate in an environment-friendly way and force them towards more of an eco-style. Accordingly, like with Gholami et al. [21] and Deng and Ji [6], we assumed that mimetic pressure and coercive pressure will positively affect the organizational attitude to Green IS $\left(\mathrm{H}_{1}\right.$ and $\left.\mathrm{H}_{2 b}\right)$, while coercive pressure is positively associated with a sustainability-oriented organization strategy $\left(\mathrm{H}_{2 \mathrm{a}}\right)$. However, it has been found that Green IS implementation is not a pure organizational phenomenon driven by external pressures but a collective behavior involving individual and institutional effort for the ecological goal at large [68]. Therefore, we agree with Gholami et al. [21] who argued that managers' attitudes and beliefs about the natural environment motivate organizational action to intensify Green IS adoption $\left(\mathrm{H}_{5 \mathrm{a}}\right)$. Further, we presumed that the manager's personal attitude to the environment is positively influenced by their attitude to the future $\left(\mathrm{H}_{4}\right)$ and by their social network $\left(\mathrm{H}_{3}\right)$. In our opinion, if a person is concerned about the future, they are most likely also concerned about the environment. Besides, some prior studies suggested a positive correlation between social network use and attitudes about the environment ([74] as cited in [1]). Finally, similarly as Loeser et al. [9], we conceptualized personal attitude to the environment and organizational attitude to Green IS as an antecedent of a sustainably oriented organizational strategy $\left(\mathrm{H}_{5 \mathrm{~b}}\right.$ and $\left.\mathrm{H}_{6 \mathrm{a}}\right)$. The authors [9] also provided evidence suggesting that environmental orientation of an organization positively affects the implementation of Green IS practices. Therefore, we presumed in our model that the organizational attitude to Green IS is positively associated with the Green IS practices, i.e., the use of IS for preventing pollution $\left(\mathrm{H}_{6 \mathrm{~b}}\right)$, product stewardship $\left(\mathrm{H}_{6 \mathrm{c}}\right)$, and sustainable development $\left(\mathrm{H}_{6 \mathrm{~d}}\right)$.

Arising from the above discussion, we present our research model in Figure 1, and summarize the proposed hypotheses as follows: 


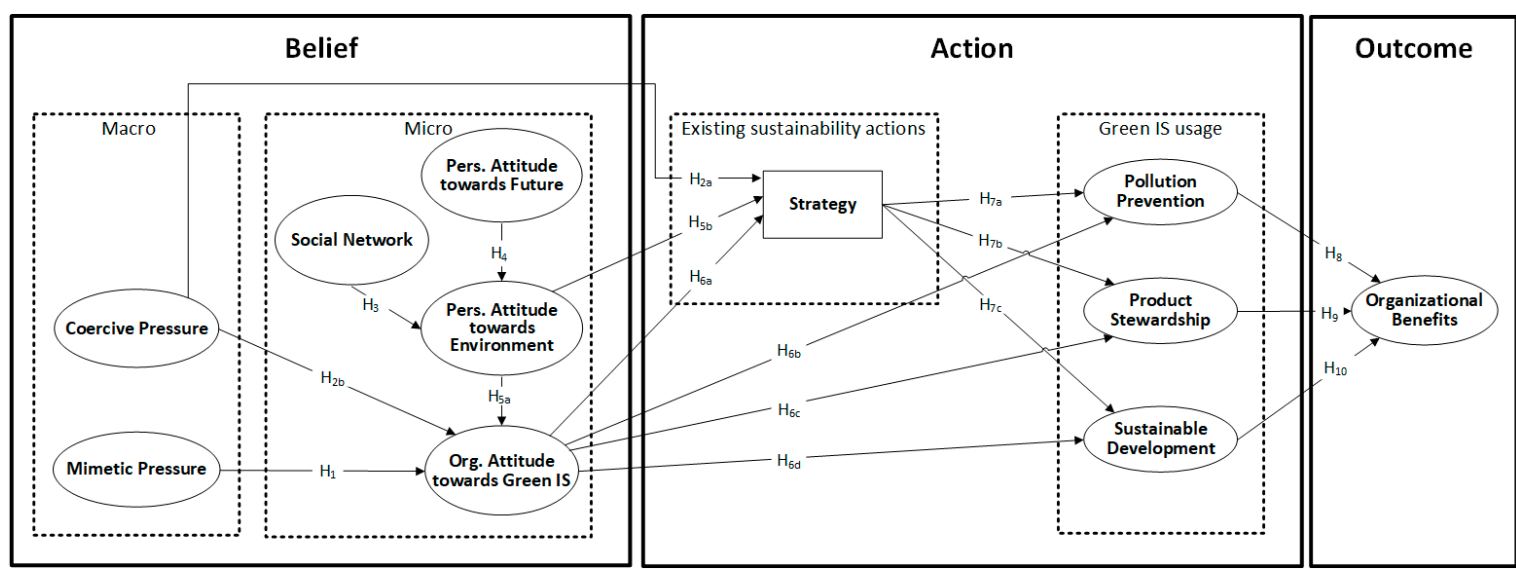

Figure 1. Conceptual model of the drivers and outcomes of Green information system (IS) adoption in small and medium-sized enterprises (SMEs).

Hypothesis $\mathbf{1}\left(\mathbf{H}_{\mathbf{1}}\right)$. Mimetic pressure is positively associated with the organizational attitude to Green IS.

Hypothesis 2a $\left(\mathbf{H}_{2 \mathbf{a}}\right)$. Coercive pressure is positively associated with a sustainability-oriented organization strategy.

Hypothesis $\mathbf{2 b}\left(\mathbf{H}_{\mathbf{2 b}}\right)$. Coercive pressure is positively associated with the organizational attitude to Green IS.

Hypothesis $3\left(\mathbf{H}_{3}\right)$. The manager's social network is positively associated with their personal attitude to the environment.

Hypothesis $\left.4 \mathbf{(} \mathbf{H}_{\mathbf{4}}\right)$. The manager's attitude to the future is positively associated with their personal attitude to the environment.

Hypothesis $\mathbf{5 a}\left(\mathbf{H}_{5 \mathbf{a}}\right)$. The manager's attitude to the environment is positively associated with the organizational attitude to Green IS.

Hypothesis $\mathbf{5 b}\left(\mathbf{H}_{\mathbf{5 b}}\right)$. The manager's attitude to the environment is positively associated with a sustainability-oriented organization strategy.

Hypothesis $6 \mathbf{a}\left(\mathbf{H}_{6 \mathbf{a}}\right)$. The organizational attitude to Green IS is positively associated with a sustainability-oriented organization strategy.

Hypothesis $\mathbf{6 b}\left(\mathbf{H}_{\mathbf{6 b}}\right)$. The organizational attitude to Green IS is positively associated with the use of IS for preventing pollution.

Hypothesis $6 \mathbf{c}\left(\mathbf{H}_{6 \mathrm{c}}\right)$. The organizational attitude to Green IS is positively associated with the use of IS for product stewardship.

Hypothesis $\mathbf{6 d}\left(\mathbf{H}_{\mathbf{6 d}}\right)$. The organizational attitude to Green IS is positively associated with the use of IS for sustainable development.

Hypothesis $7 \mathbf{a}\left(\mathbf{H}_{7 \mathbf{a}}\right)$. A sustainability-oriented organization strategy is positively associated with the use of IS for preventing pollution.

Hypothesis $7 \mathbf{b}\left(\mathbf{H}_{7 \mathbf{b}}\right)$. A sustainability-oriented organization strategy is positively associated with the use of IS for product stewardship. 
Hypothesis $\mathbf{7 c}\left(\mathbf{H}_{7 \mathrm{c}}\right)$. A sustainability-oriented organization strategy is positively associated with the use of IS for sustainable development.

Hypothesis $\mathbf{8}\left(\mathbf{H}_{\mathbf{8}}\right)$. The use of IS for preventing pollution is positively associated with organizational benefits.

Hypothesis $\mathbf{9}\left(\mathbf{H}_{\mathbf{9}}\right)$. The use of IS for product stewardship is positively associated with organizational benefits.

Hypothesis $10\left(\mathbf{H}_{\mathbf{1 0}}\right)$. The use of IS for sustainable development is positively associated with organizational benefits.

\section{Materials and Methods}

\subsection{Questionnaire Development}

In order to apply the model shown in Figure 1, we developed a questionnaire in which every model construct was represented by several indicators (i.e., questions). The total number of measured indicators was 40 (see Table 1), where most of them were adapted from instruments validated in previous studies (e.g., [21,28]). Almost all indicators were measured on a 5-point, Likert-type scale of agreement, with 1 meaning strongly disagree, and 5 strongly agree. The question regarding the presence of sustainable development principles within the organizational strategy was answered with "yes" or "no".

\subsection{Data Collection and Sample Characteristics}

A web survey was performed in which 3,623 randomly selected SMEs from Slovenia (representing $2 \%$ of all Slovenian SMEs) were invited to collaborate. This sample matched the demographic structure of Slovenian SMEs according to their region and main activity.

We received 210 survey responses; of these, 54 were incomplete and were thus omitted from further analysis. The final sample size was therefore 156 SMEs (23.7\% having up to 9 employees, $48.1 \%$ having $10-49$ employees, and $28.2 \%$ having 50 to 249 employees). The SMEs participating in the survey come from different areas (classified according to [75]), where the biggest share of them (14.1\%) are from Other Service Activities, $11.4 \%$ from Information and Communication, and 8.7\% from Manufacturing.

The invitation to participate in the survey was addressed to SMEs' managers who were asked to forward the survey to the SME's CIO or another person with profound IS knowledge. Regarding the respondents' position, $20.8 \%$ of them were CEOs, $20.1 \%$ heads of departments, $13.2 \%$ CIOs, $4.2 \%$ external IS consultants, while $41.7 \%$ of the respondents listed another job position; $53.7 \%$ of them were male and $46.3 \%$ female, where the respondents' age varies from 24 to 61 years $(M=43.11$ years, $S D=9.33$ years).

\subsection{Statistical Methods}

Data obtained from the survey were analyzed using the PLS-SEM approach with R package plspm [76,77]. PLS-SEM may be used when only a small sample is available to estimate the relationships between the model constructs with several indicators [78-80].

The analysis was performed using the standard two-stage approach, wherein first the measurement model and, second, the structural model were evaluated [77]. In the first step, the measurement model was assessed to determine how well the indicators reflect the theoretical latent variables. In step two, the structural relationships among the model constructs were tested. The PLS-SEM results are presented with the values of the path coefficient (representing the relationships between the model constructs) together with the $t$-statistics values (calculated based on model validation using the bootstrap procedure) and the significance level. Further, for each endogenous latent variable of the model a coefficient of determination $\left(R^{2}\right)$ was calculated, representing the percentage share of the variance explained by the set of the predictors for that variable. 


\section{Results}

\subsection{Descriptive Statistics}

First, descriptive statistics were calculated for all model constructs as well as their indicators. The results are listed in Table 1.

Table 1. Descriptive statistics for the model constructs and corresponding indicators.

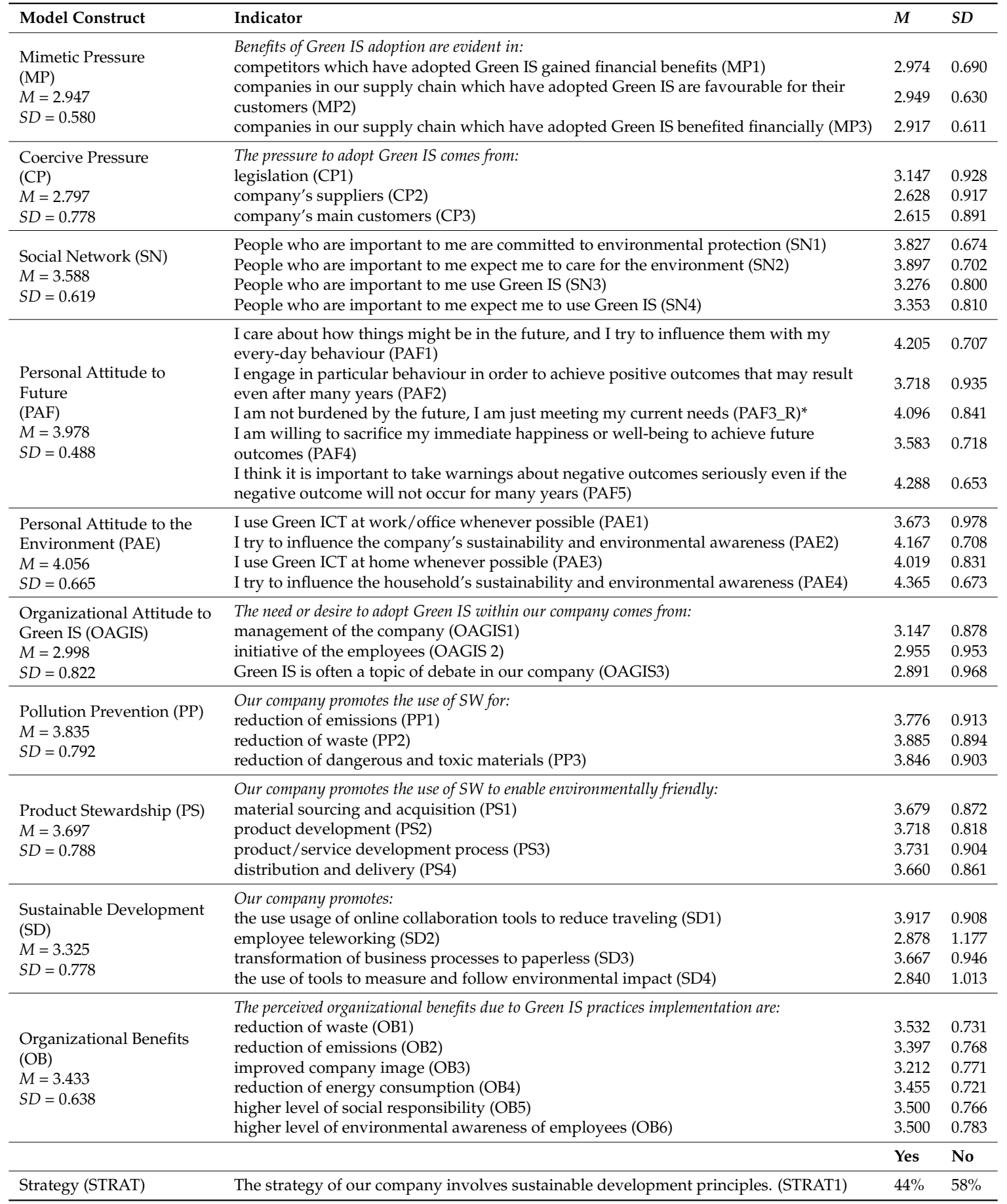

* The original wording of the indicator PAF3 was stated negatively. Prior the analysis, this indicator was recoded and labelled PAF3_R. 


\subsection{Evaluation of the Measurement Model}

According to Ravand and Baghaei [79], the measurement model is evaluated in terms of the unidimensionality of the latent variables, convergent validity, and discriminant validity. The unidimensionality of latent variables is assessed by Cronbach's alpha, composite reliability through Dillon-Goldstein's rho (both indices should exceed 0.7), and principal component analysis by examining the first two eigenvalues where the first eigenvalue should be larger than 1 and the second one much lower, below 1.

Convergent validity is achieved when the average variance extracted $(A V E)$ (measuring the amount of variance captured by the model construct relative to the amount of variance attributable to measurement error) of each construct exceeds 0.5 [80] and the factor loadings of its indicators are above 0.7 [79].

The model's discriminant validity is examined in two ways: first, by analysis of the indicators' loadings and cross-loadings and, second, by comparing the value of the square root of $A V E$ of each construct with the correlations between other constructs. To prove discriminant validity, the loadings of the indicators of a particular construct must be greater than the corresponding cross-loadings, while the values of the square root of $A V E$ for a particular construct must be greater than the corresponding correlations between other constructs [80].

While evaluating the measurement model, it was found that loadings of the indicators PAF4 and PAF3_R (see Table 1) were below 0.7 (0.336 and 0.591 , respectively, with AVE equal to 0.399 and 0.472 ). Therefore, these indicators were removed from the model in two sequential steps. Results of the final model's evaluation are shown in Tables 2-4.

The results presented in Table 2 show the values of Cronbach's alpha and Dillon-Goldstein's rho easily satisfy the criterion of being larger than 0.7 for each latent variable. Further, the values of eigenvalues also prove the measurement model's unidimensionality.

Table 3 reveals that almost all the factor loadings are larger than 0.7. One exception is the loading of the indicator PAF5 that is slightly below 0.7 (0.651). According to Esfahani et al. [33], this is not critical since the loading factor is above 0.4 while other indices of the PAF construct are well above the desired thresholds (composite reliability through Dillon-Goldstein's rho is $0.806>0.7$ (Table 2) and the corresponding $A V E$ value is $0.580>0.5$ (Table 4)). Moreover, Table 4 shows the values of $A V E$ for all constructs exceed 0.5 (the smallest is for PAF 0.580), indicating the model has high convergent validity.

Table 2. Evaluation of the unidimensionality of latent variables.

\begin{tabular}{cccccc}
\hline $\begin{array}{c}\text { Latent } \\
\text { Variable }\end{array}$ & $\begin{array}{c}\text { No. of } \\
\text { Indicators }\end{array}$ & $\begin{array}{c}\text { Cronbach's } \\
\text { Alpha }\end{array}$ & $\begin{array}{c}\text { Dillon-Goldstein's } \\
\text { Rho }\end{array}$ & $\begin{array}{c}\text { 1st } \\
\text { Eigenvalue }\end{array}$ & $\begin{array}{c}\text { 2nd } \\
\text { Eigenvalue }\end{array}$ \\
\hline MP & 3 & 0.884 & 0.929 & 2.440 & 0.374 \\
CP & 3 & 0.814 & 0.891 & 2.198 & 0.594 \\
SN & 4 & 0.848 & 0.898 & 2.747 & 0.820 \\
PAF & 3 & 0.638 & 0.806 & 1.748 & 0.753 \\
PAE & 4 & 0.853 & 0.901 & 2.783 & 0.596 \\
OAGIS & 3 & 0.856 & 0.912 & 2.329 & 0.352 \\
PP & 3 & 0.850 & 0.909 & 2.310 & 0.455 \\
PS & 4 & 0.932 & 0.952 & 3.326 & 0.327 \\
SD & 4 & 0.768 & 0.852 & 2.363 & 0.653 \\
OB & 6 & 0.918 & 0.937 & 4.282 & 0.610 \\
\hline
\end{tabular}


Table 3. Loadings (in bold) and cross-loadings of the model constructs and their indicators.

\begin{tabular}{|c|c|c|c|c|c|c|c|c|c|c|c|c|}
\hline \multirow{2}{*}{$\begin{array}{l}\text { Model } \\
\text { Construct }\end{array}$} & \multirow{2}{*}{ Indicator } & \multicolumn{11}{|c|}{ Model Construct } \\
\hline & & MP & $\mathrm{CP}$ & SN & PAF & PAE & OAGIS & STRAT & PP & PS & SD & OB \\
\hline \multirow{3}{*}{ MP } & MP1 & 0.846 & 0.209 & 0.186 & 0.195 & 0.106 & 0.191 & 0.052 & 0.292 & 0.290 & 0.312 & 0.082 \\
\hline & MP2 & 0.932 & 0.374 & 0.209 & 0.223 & 0.199 & 0.234 & 0.114 & 0.282 & 0.293 & 0.272 & 0.148 \\
\hline & MP3 & 0.923 & 0.349 & 0.194 & 0.170 & 0.166 & 0.248 & 0.079 & 0.268 & 0.306 & 0.256 & 0.133 \\
\hline \multirow{3}{*}{$\mathrm{CP}$} & CP1 & 0.247 & 0.808 & 0.386 & 0.162 & 0.227 & 0.449 & 0.277 & 0.317 & 0.264 & 0.404 & 0.336 \\
\hline & CP2 & 0.314 & 0.907 & 0.281 & 0.187 & 0.116 & 0.395 & 0.263 & 0.286 & 0.293 & 0.349 & 0.197 \\
\hline & CP3 & 0.347 & 0.844 & 0.239 & 0.172 & 0.110 & 0.375 & 0.342 & 0.269 & 0.292 & 0.346 & 0.219 \\
\hline \multirow{4}{*}{ SN } & SN1 & 0.094 & 0.179 & 0.805 & 0.329 & 0.282 & 0.372 & 0.191 & 0.256 & 0.249 & 0.271 & 0.305 \\
\hline & SN2 & 0.117 & 0.276 & 0.857 & 0.324 & 0.252 & 0.467 & 0.241 & 0.271 & 0.239 & 0.354 & 0.326 \\
\hline & SN3 & 0.251 & 0.354 & 0.806 & 0.169 & 0.206 & 0.510 & 0.226 & 0.349 & 0.341 & 0.353 & 0.384 \\
\hline & SN4 & 0.258 & 0.382 & 0.843 & 0.210 & 0.338 & 0.584 & 0.283 & 0.435 & 0.427 & 0.478 & 0.407 \\
\hline \multirow{3}{*}{ PAF } & PAF1 & 0.230 & 0.170 & 0.277 & 0.820 & 0.331 & 0.215 & 0.199 & 0.235 & 0.306 & 0.225 & 0.175 \\
\hline & PAF2 & 0.072 & 0.150 & 0.225 & 0.802 & 0.377 & 0.230 & 0.242 & 0.204 & 0.335 & 0.233 & 0.199 \\
\hline & PAF5 & 0.223 & 0.148 & 0.218 & 0.651 & 0.253 & 0.181 & 0.121 & 0.114 & 0.138 & 0.140 & 0.098 \\
\hline \multirow{4}{*}{ PAE } & PAE1 & 0.202 & 0.200 & 0.285 & 0.351 & 0.804 & 0.372 & 0.285 & 0.536 & 0.533 & 0.361 & 0.312 \\
\hline & PAE2 & 0.142 & 0.113 & 0.241 & 0.369 & 0.831 & 0.344 & 0.265 & 0.368 & 0.364 & 0.209 & 0.248 \\
\hline & PAE3 & 0.141 & 0.171 & 0.340 & 0.341 & 0.894 & 0.299 & 0.229 & 0.430 & 0.347 & 0.263 & 0.277 \\
\hline & PAE4 & 0.099 & 0.117 & 0.247 & 0.368 & 0.803 & 0.243 & 0.246 & 0.318 & 0.278 & 0.220 & 0.240 \\
\hline \multirow{3}{*}{ OAGIS } & OAGIS1 & 0.263 & 0.464 & 0.566 & 0.246 & 0.367 & 0.891 & 0.336 & 0.474 & 0.433 & 0.523 & 0.543 \\
\hline & OAGIS2 & 0.161 & 0.347 & 0.500 & 0.239 & 0.298 & 0.867 & 0.314 & 0.362 & 0.420 & 0.417 & 0.453 \\
\hline & OAGIS3 & 0.228 & 0.449 & 0.480 & 0.243 & 0.334 & 0.884 & 0.261 & 0.357 & 0.316 & 0.501 & 0.482 \\
\hline STRAT & STRAT1 & 0.092 & 0.344 & 0.287 & 0.254 & 0.308 & 0.346 & 1.000 & 0.390 & 0.423 & 0.395 & 0.366 \\
\hline \multirow{3}{*}{ PP } & PP1 & 0.242 & 0.326 & 0.396 & 0.199 & 0.436 & 0.454 & 0.333 & 0.886 & 0.623 & 0.472 & 0.411 \\
\hline & PP2 & 0.246 & 0.299 & 0.356 & 0.235 & 0.455 & 0.419 & 0.390 & 0.926 & 0.623 & 0.438 & 0.380 \\
\hline & PP3 & 0.345 & 0.277 & 0.301 & 0.223 & 0.428 & 0.312 & 0.296 & 0.816 & 0.652 & 0.441 & 0.292 \\
\hline \multirow{4}{*}{ PS } & PS1 & 0.258 & 0.263 & 0.336 & 0.287 & 0.355 & 0.396 & 0.373 & 0.619 & 0.889 & 0.470 & 0.346 \\
\hline & PS2 & 0.329 & 0.293 & 0.349 & 0.312 & 0.469 & 0.415 & 0.403 & 0.686 & 0.930 & 0.529 & 0.341 \\
\hline & PS3 & 0.301 & 0.317 & 0.365 & 0.346 & 0.449 & 0.422 & 0.424 & 0.651 & 0.941 & 0.532 & 0.297 \\
\hline & PS4 & 0.310 & 0.341 & 0.359 & 0.356 & 0.410 & 0.382 & 0.337 & 0.657 & 0.885 & 0.484 & 0.299 \\
\hline \multirow{4}{*}{ SD } & SD1 & 0.228 & 0.333 & 0.424 & 0.306 & 0.330 & 0.448 & 0.339 & 0.354 & 0.421 & 0.774 & 0.359 \\
\hline & SD2 & 0.109 & 0.208 & 0.255 & 0.126 & 0.152 & 0.348 & 0.235 & 0.249 & 0.295 & 0.765 & 0.237 \\
\hline & SD3 & 0.248 & 0.226 & 0.337 & 0.138 & 0.258 & 0.370 & 0.233 & 0.407 & 0.428 & 0.760 & 0.296 \\
\hline & SD4 & 0.312 & 0.483 & 0.324 & 0.207 & 0.210 & 0.474 & 0.359 & 0.506 & 0.504 & 0.759 & 0.379 \\
\hline \multirow{6}{*}{ OB } & OB1 & 0.139 & 0.173 & 0.379 & 0.176 & 0.295 & 0.444 & 0.359 & 0.381 & 0.303 & 0.273 & 0.818 \\
\hline & OB2 & 0.131 & 0.285 & 0.375 & 0.162 & 0.241 & 0.443 & 0.263 & 0.312 & 0.264 & 0.371 & 0.803 \\
\hline & OB3 & 0.041 & 0.370 & 0.307 & 0.176 & 0.155 & 0.397 & 0.309 & 0.317 & 0.246 & 0.273 & 0.734 \\
\hline & OB4 & 0.082 & 0.268 & 0.328 & 0.164 & 0.247 & 0.531 & 0.334 & 0.294 & 0.237 & 0.408 & 0.860 \\
\hline & OB5 & 0.155 & 0.230 & 0.388 & 0.194 & 0.334 & 0.504 & 0.296 & 0.374 & 0.341 & 0.414 & 0.916 \\
\hline & OB6 & 0.130 & 0.227 & 0.398 & 0.205 & 0.340 & 0.524 & 0.306 & 0.416 & 0.372 & 0.415 & 0.922 \\
\hline
\end{tabular}

Table 4. Average Variance Extracted ( $A V E$ ), square root of $A V E$ (on the diagonal), and correlations corrected for attenuation among the model constructs.

\begin{tabular}{|c|c|c|c|c|c|c|c|c|c|c|c|c|}
\hline \multirow{2}{*}{ Constr. } & \multirow{2}{*}{$A V E$} & \multicolumn{11}{|c|}{ Correlations Corrected for Attenuation } \\
\hline & & MP & $\mathrm{CP}$ & SN & PAF & PAE & OAGIS & STRAT & PP & PS & SD & OB \\
\hline MP & 0.812 & 0.901 & & & & & & & & & & \\
\hline $\mathrm{CP}$ & 0.729 & 0.352 & 0.854 & & & & & & & & & \\
\hline SN & 0.685 & 0.218 & 0.360 & 0.828 & & & & & & & & \\
\hline PAF & 0.580 & 0.216 & 0.203 & 0.313 & 0.762 & & & & & & & \\
\hline PAE & 0.695 & 0.177 & 0.182 & 0.335 & 0.428 & 0.834 & & & & & & \\
\hline OAGIS & 0.775 & 0.251 & 0.480 & 0.587 & 0.276 & 0.380 & 0.881 & & & & & \\
\hline STRAT & 1.000 & 0.092 & 0.344 & 0.287 & 0.254 & 0.308 & 0.346 & 1.000 & & & & \\
\hline PP & 0.769 & 0.309 & 0.343 & 0.402 & 0.248 & 0.500 & 0.456 & 0.390 & 0.877 & & & \\
\hline PS & 0.831 & 0.328 & 0.331 & 0.386 & 0.356 & 0.462 & 0.444 & 0.423 & 0.716 & 0.912 & & \\
\hline SD & 0.584 & 0.307 & 0.433 & 0.447 & 0.268 & 0.319 & 0.549 & 0.395 & 0.512 & 0.553 & 0.764 & \\
\hline OB & 0.713 & 0.137 & 0.300 & 0.431 & 0.213 & 0.325 & 0.563 & 0.366 & 0.416 & 0.352 & 0.429 & 0.844 \\
\hline
\end{tabular}

Loadings of the indicators of each model construct are denoted with bold in Table 3. It may be seen from Table 3 that the loadings of the indicators of each model construct are larger than the 
corresponding cross-loadings. The correlations between the model's constructs are shown in the right panel of Table 4, while the diagonal elements in the correlation matrix that have a value of 1 are replaced by the values of the square root of $A V E$. It is evident that the values of the square root of $A V E$ for the corresponding model construct are all greater than the interconstruct correlations. This shows the indicators have more in common with the construct they are associated with than they do with the other constructs. Therefore, discriminant validity can be inferred for all model constructs.

To summarize the measurement model evaluation, the unidimensionality, convergent validity, and discriminant validity indices were all above their recommended thresholds and therefore the developed measurement model is reliable and valid for use in assessing the structural model of the study.

\subsection{Evaluation of the Structural Model and Hypotheses Testing}

The structural model presented in Figure 1 was evaluated by estimating paths between the model constructs. Results are listed in Table 5 where it can be seen that 15 of the 17 hypotheses were supported, while 2 were rejected.

Table 5. Results of the structural model evaluation and hypotheses testing.

\begin{tabular}{cccccc}
\hline Hypothesis & Path & Path Coefficient & t-Statistics & Hyp. Supported & Sig. Level \\
\hline $\mathrm{H}_{1}$ & $\mathrm{MP} \rightarrow$ OAGIS & 0.053 & 0.741 & No & n.s. \\
$\mathrm{H}_{2 \mathrm{a}}$ & $\mathrm{CP} \rightarrow$ STRAT & 0.235 & 2.842 & Yes & $* *$ \\
$\mathrm{H}_{2 \mathrm{~b}}$ & $\mathrm{CP} \rightarrow$ OAGIS & 0.406 & 5.630 & Yes & $* * *$ \\
$\mathrm{H}_{3}$ & $\mathrm{SN} \rightarrow$ PAE & 0.222 & 2.973 & Yes & $* *$ \\
$\mathrm{H}_{4}$ & $\mathrm{PAF} \rightarrow$ PAE & 0.359 & 4.798 & Yes & $* * *$ \\
$\mathrm{H}_{5 \mathrm{a}}$ & PAE $\rightarrow$ OAGIS & 0.299 & 4.368 & Yes & $* * *$ \\
$\mathrm{H}_{5 \mathrm{~b}}$ & PAE $\rightarrow$ STRAT & 0.208 & 2.643 & Yes & $* *$ \\
$\mathrm{H}_{6 \mathrm{a}}$ & OAGIS $\rightarrow$ & 0.155 & 1.765 & Yes & $*$ \\
$\mathrm{H}_{6 \mathrm{~b}}$ & STRAT & 0.366 & 4.975 & Yes & $* * *$ \\
$\mathrm{H}_{6 \mathrm{c}}$ & OAGIS $\rightarrow$ PP & 0.338 & 4.623 & Yes & $* * *$ \\
$\mathrm{H}_{6 \mathrm{~d}}$ & OAGIS $\rightarrow$ SD & 0.467 & 6.710 & Yes & $* * *$ \\
$\mathrm{H}_{7 \mathrm{a}}$ & STRAT $\rightarrow$ PP & 0.263 & 3.571 & Yes & $* * *$ \\
$\mathrm{H}_{7 \mathrm{~b}}$ & STRAT $\rightarrow$ PS & 0.306 & 4.177 & Yes & $* * *$ \\
$\mathrm{H}_{7 \mathrm{c}}$ & STRAT $\rightarrow$ SD & 0.231 & 3.315 & Yes & $* * *$ \\
$\mathrm{H}_{8}$ & PP $\rightarrow$ OB & 0.269 & 2.599 & Yes & $* * *$ \\
$\mathrm{H}_{9}$ & PS $\rightarrow$ OB & -0.001 & -0.006 & No & n.s. \\
$\mathrm{H}_{10}$ & SD $\rightarrow$ OB & 0.290 & 3.348 & Yes & $* * *$ \\
\hline & $* p<0.05 ; * *<0.01 ; * * *<0.001$. & &
\end{tabular}

Figure 2 shows the evaluated structural model. The coefficient of determination $R^{2}$ is also calculated for every endogenous latent variable. This coefficient determines the model's predictive capability if its value is greater than 0.1 [81]. Figure 2 reveals that all values of $R^{2}$ fulfil this requirement.

Since PLS-SEM is a nonparametric statistical procedure, the significance of the path coefficients and the precision of the estimates should be checked through standard errors provided by bootstrap validation [79]. As suggested by Chin [82] and Hair et al. [83], 500 samples were drawn in the bootstrap validation. Results of the bootstrap validation of the structural model and testing the significance of the path coefficients are given in Table 6, while the results of the bootstrap evaluation of the factor loadings are included in the Appendix A.

The values of the $t$-statistics in Table 6 are calculated as the original path divided by the standard error from the bootstrap [84]. The significance of the path coefficients is examined based on the value of $t$-statistics and corresponding critical values $t_{0.05}, t_{0.01}$, and $t_{0.001}$. The results provided in Table 6 show that all coefficients of paths were indicated to be significant, and can be proclaimed as significantly different from zero. 


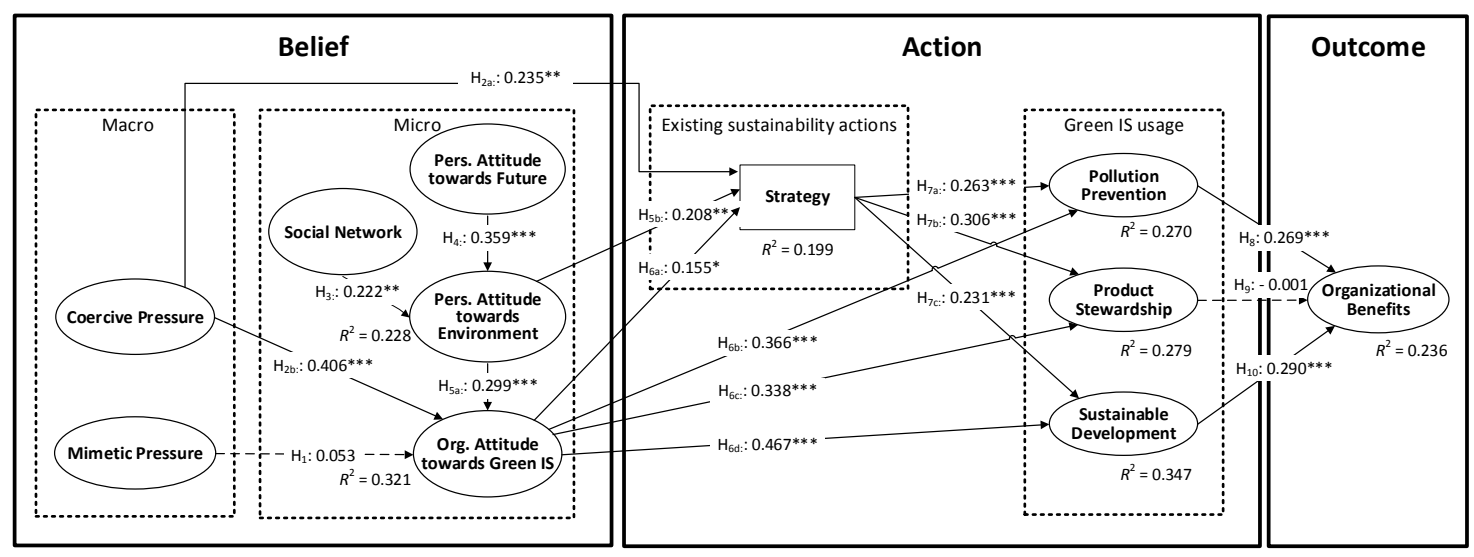

Figure 2. The evaluated relationships among the structural model constructs.

Table 6. Results of bootstrap validation of the structural model and path coefficients significance testing.

\begin{tabular}{|c|c|c|c|c|c|c|c|c|c|}
\hline Hypothesis & Path & $\begin{array}{l}\text { Original } \\
\text { Path }\end{array}$ & MeanBoot & $\begin{array}{l}\text { Std. } \\
\text { Error }\end{array}$ & Perc.025 & Perc.975 & $t$-Statistics & $\begin{array}{l}\text { Path Coef. } \\
\text { Sign. }\end{array}$ & $\begin{array}{l}\text { Sig. } \\
\text { Level }\end{array}$ \\
\hline $\mathrm{H}_{1}$ & $\mathrm{MP} \rightarrow$ OAGIS & 0.053 & 0.060 & 0.076 & -0.089 & 0.202 & 0.698 & No & n.s. \\
\hline $\mathrm{H}_{2 \mathrm{a}}$ & $\mathrm{CP} \rightarrow \mathrm{STRAT}$ & 0.235 & 0.238 & 0.077 & 0.065 & 0.380 & 6.103 & Yes & $* * *$ \\
\hline $\mathrm{H}_{3}$ & $\mathrm{SN} \rightarrow \mathrm{PAE}$ & 0.222 & 0.223 & 0.079 & 0.072 & 0.379 & 2.830 & Yes & $* *$ \\
\hline $\mathrm{H}_{4}$ & $\mathrm{PAF} \rightarrow \mathrm{PAE}$ & 0.359 & 0.364 & 0.067 & 0.247 & 0.496 & 5.389 & Yes & $* * *$ \\
\hline $\mathrm{H}_{5 \mathrm{a}}$ & PAE $\rightarrow$ OAGIS & 0.299 & 0.294 & 0.070 & 0.157 & 0.428 & 4.254 & Yes & $* * *$ \\
\hline $\mathrm{H}_{6 \mathrm{~b}}$ & OAGIS $\rightarrow$ PP & 0.366 & 0.365 & 0.068 & 0.221 & 0.498 & 5.374 & Yes & $* * *$ \\
\hline $\mathrm{H}_{6 \mathrm{c}}$ & OAGIS $\rightarrow$ PS & 0.338 & 0.337 & 0.082 & 0.165 & 0.499 & 4.105 & Yes & $* * *$ \\
\hline $\mathrm{H}_{6 \mathrm{~d}}$ & $\mathrm{OAGIS} \rightarrow \mathrm{SD}$ & 0.467 & 0.466 & 0.063 & 0.346 & 0.589 & 7.363 & Yes & $* * *$ \\
\hline $\mathrm{H}_{7 \mathrm{a}}$ & STRAT $\rightarrow$ PP & 0.263 & 0.264 & 0.067 & 0.124 & 0.383 & 3.913 & Yes & $* * *$ \\
\hline $\mathrm{H}_{7 \mathrm{~b}}$ & STRAT $\rightarrow$ PS & 0.306 & 0.308 & 0.071 & 0.165 & 0.436 & 4.307 & Yes & $* * *$ \\
\hline
\end{tabular}

\section{Discussion}

Drawing on the theoretical framework of the BAO [1], we investigated whether internal and external drivers affect Green IS adoption, and to what extent different Green IS initiatives enhance performance outcomes. The embedding of green sustainability in SMEs has received growing attention in research (e.g., [85]), yet our understanding of the antecedents and consequences of Green IS adoption in SMEs remains relatively unclear. Our study underscores previous conceptual assertions (e.g., [86]) advocating the importance of SMEs adopting an information system to support their sustainable development efforts. In this regard, the present study extends understanding to the conceptual mechanisms by which SMEs adopt Green IS, especially by a consideration of the context in which it occurs (i.e., coercive pressure and internal attitude to green initiatives as driving forces) and, specifically, by examining the actions towards Green IS adoption and their performance implications. Therefore, this study adds to the environmental management and Green IS literature in several important and distinct ways. For instance, current environmental management studies do not provide clear evidence of the performance benefits of environmental initiatives, particularly of Green IS adoption in SMEs. In this respect, the present study establishes a link between personal attitudes, institutional mechanisms, internal environmental/sustainability initiatives and performance implications.

The study findings show that, while there is no association between mimetic pressure and organizational attitude to Green IS, the former is positively influenced by coercive pressure. This then suggests that formal rules, regulations, and pressures from powerful stakeholders on which the organizations are dependent are considered as important factors that drive an organization (especially 
an SME) to include Green IS in its sustainability strategy. Institutional theory has also been applied in previous studies [87] that examined Green IS, particularly for identifying driving forces or motives behind organizational endeavor to become a more sustainable company. By focusing on the SME context, our study extends previous studies on Green IS that used institutional theory as a theoretical lens to study the organizational response to environmental issues [6,21]. Similarly to the study of Bose and Luo [88] and Chen et al. [10], our study excluded normative pressure to avoid any potential confounding between normative, mimetic, and coercive pressures. Engert et al. [89] provided a thorough literature review to systematically summarize the internal and external drivers of sustainability as well as to emphasize the supporting and hindering factors with respect to integrating corporate sustainability. The findings of that research can, to some extent, substantiate our results, suggesting that manager and employee attitude is essential for integrating sustainability into strategic management. However, as far as the internalization (i.e., embedding Green IS practices into daily practice) of Green IS is concerned, SMEs often face certain constraints such as a skills deficit and knowledge limitations $[90,91]$.

Our findings show that both preventing pollution and sustainable development are effective sources of perceived organizational benefits. These findings further confirm previous studies (e.g., [21]) which found support for arguments regarding the positive impact of Green IS on an enterprise's environmental performance. Further, Green IS adoption may also be conceived as a source of innovation [92] that can ultimately bring competitive advantage [93]. The findings of our study hence demonstrate the importance of Green IS adoption for predicting performance outcomes. In particular, the SME research context used in this study contributes to the literature on Green IS, chiefly by highlighting the mechanisms through which an enterprise can gain performance benefits. Although our study did not test the link between Green IS and economic performance, one may argue that enhancing organizational benefits could ultimately lead to enhanced economic performance. Earlier studies (e.g., [94]) also suggest there might be a reciprocal causal mechanism linking environmental performance and economic performance. However, this is not necessarily the case for SMEs since a lack of resources often leads them to be less willing to invest in new technologies, especially concerning the payback period $[19,91]$. Our results allow the argument that SMEs have room for improvement in the area of adopting tools and technologies that support sustainable development goals.

\section{Managerial Implications}

The results of our study demonstrate that organizations would benefit from efforts to adopt and maintain Green IS. Key factors that foster Green IS adoption in SMEs are: external pressures from a diverse range of stakeholders (e.g., customers, suppliers, governmental agencies, etc.); internal perception, knowledge, and attitude to environmental issues; strategic orientation of an organization. The positive impacts of employee and organizational attitude to Green IS convey an important message for organizations by highlighting the need to enhance employees' engagement in pro-environmental behaviors [95]. Thus, managers should be aware of the important role they play in building a green climate, especially as concerns the attitudes and behaviors that are valued among employees. The manager should first ensure the organization's motivation for implementing Green IS is internally oriented rather than being merely externally oriented. Moreover, it is essential to include the Green IS adoption on the strategic level of the organization by having a clear prioritization of the organization's sustainability initiatives in mind.

\section{Conclusions}

This study enhances understanding of the use of Green IS in translating sustainability strategy into organizational performance outcomes. Therefore, the presented framework can help scientists and managers identify the potential implications of adopting Green IS. Despite growth in Green IS in recent years, practice is still mainly in the domain of large companies and often associated with notions of expense for small companies. This study aims to fill this research gap by indicating that Green IS 
is an important driver for making SMEs be more efficient and effective. In light of this, the current study outlines the importance of examining use of Green IS from a comprehensive perspective that guides SMEs in assessing their approach to Green IS adoption and deployment. Accordingly, it helps organizations identify appropriate Green IS initiatives as a way of achieving organizational benefits through effective implementation of a sustainability strategy. More specifically, the study highlights the importance of the beliefs, actions, and outcomes of Green IS adoption. Given the importance of Green IS in implementing a sustainability strategy, managers should be aware that simply integrating Green IS initiatives into strategy might not help their organizations achieve their performance goals. In addition, special attention should be paid to enhance employees' attitudes to green issues and Green IS. It is crucial to understand that organizational attitudes to Green IS can directly and indirectly via strategy effect the extent to which SMEs use Green IS, which ultimately leads to enhanced performance outcomes. The main conclusion to be drawn from this study is that there are distinct internal and external critical areas that should be considered by SMEs wishing to implement Green IS effectively. In this regard, the present study proposes a novel research model to explore both the antecedents and consequents of Green IS adoption in SMEs.

\section{Limitations and Future Directions}

Despite its many contributions, this research is also not without limitations. First, this study resorted to perceptual measures for measuring performance outcomes. While this is still acceptable, future studies could improve this area by using real metric and objective data wherever available. Notwithstanding the fact that considerable effort and time was devoted to developing the measurements, and the fact that PLS-SEM analyses meet most of the acceptable criteria, room remains to improve the research model. As such, future studies may extend other perspectives by integrating additional attributes and properties into these constructs. Moreover, future studies could extend the context from Slovenian SMEs to those located in other countries, mainly to verify the generalizability of this study's findings and to study cultural and regional differences concerning Green IS adoption [40]. Further research on Green IS could also apply a qualitative research approach (e.g., Action design research) or a combination of qualitative and quantitative research methods (e.g., Design Science Research) to help extend and promote the research results in the business sector. This study is based on cross-sectoral industries given its position as one of the early empirical studies to investigate Green IS adoption in SMEs. Like with other cross-sectional studies, caution should be taken while interpreting the cause and effect between the variables examined in the study. Therefore, future research should consider the possibility of using longitudinal data to improve the study findings. It is also recommended that future studies focus on a single industry where the pattern of Green IS deployment is more homogeneous in order to produce more refined insights into the phenomenon under study. Research on Green IS adoption in SMEs could also involve analysis of the social networks of individuals, specifically influencers or managers, which might result in further recommendations for the promotion of Green IS.

Author Contributions: Conceptualization, A.B. (Alenka Baggia), A.B. (Alenka Brezavšček), M.M. and A.Ž.; methodology, A.B. (Alenka Brezavšček) and A.Ž.; software, A.Ž.; validation, A.B. (Alenka Baggia), A.B. (Alenka Brezavšček) and M.M.; formal analysis, A.B. (Alenka Brezavšček) and A.Ž.; investigation, A.B. (Alenka Baggia) and A.B. (Alenka Brezavšček); resources, A.B. (Alenka Baggia), A.B. (Alenka Brezavšček) and M.M.; data curation, A.Ž.; writing—original draft preparation, A.B. (Alenka Baggia), A.B. (Alenka Brezavšček), M.M. and A.Ž.; writing-review and editing, A.B. (Alenka Baggia), A.B. (Alenka Brezavšček), M.M. and A.Ž.; visualization, A.B. (Alenka Baggia); supervision, A.B. (Alenka Baggia), A.B. (Alenka Brezavšček), M.M. and A.Ž.; project administration, A.B. (Alenka Baggia) and A.B. (Alenka Brezavšček).

Funding: This research received no external funding.

Acknowledgments: This research was supported by the Slovenian Research Agency; Program No. P5-0018Decision Support Systems in Digital Business. 
Conflicts of Interest: The authors declare no conflict of interest. The funders had no role in the design of the study; in the collection, analyses, or interpretation of data; in the writing of the manuscript, or in the decision to publish the results.

\section{Appendix A}

Results of bootstrap validation for factor loadings.

\begin{tabular}{|c|c|c|c|c|c|c|}
\hline Model Construct & Indicator & Original & Mean.Boot & Std.Error & perc.025 & perc. 975 \\
\hline \multirow{3}{*}{$\begin{array}{c}\text { Mimetic Pressure } \\
(\mathrm{MP})\end{array}$} & MP1 & 0.846 & 0.843 & 0.056 & 0.710 & 0.924 \\
\hline & MP2 & 0.932 & 0.926 & 0.032 & 0.860 & 0.967 \\
\hline & MP3 & 0.923 & 0.921 & 0.030 & 0.850 & 0.962 \\
\hline \multirow{3}{*}{$\begin{array}{l}\text { Coercive Pressure } \\
\text { (CP) }\end{array}$} & $\mathrm{CP} 1$ & 0.791 & 0.786 & 0.045 & 0.683 & 0.863 \\
\hline & $\mathrm{CP} 2$ & 0.909 & 0.907 & 0.019 & 0.863 & 0.940 \\
\hline & $\mathrm{CP} 3$ & 0.861 & 0.861 & 0.031 & 0.789 & 0.912 \\
\hline \multirow{4}{*}{$\begin{array}{l}\text { Social Network } \\
\text { (SN) }\end{array}$} & SN1 & 0.805 & 0.794 & 0.070 & 0.637 & 0.883 \\
\hline & SN2 & 0.857 & 0.844 & 0.058 & 0.722 & 0.911 \\
\hline & SN3 & 0.806 & 0.794 & 0.091 & 0.622 & 0.897 \\
\hline & SN4 & 0.843 & 0.844 & 0.051 & 0.724 & 0.916 \\
\hline \multirow{3}{*}{$\begin{array}{c}\text { Personal Attitude to } \\
\text { Future } \\
\text { (PAF) }\end{array}$} & PAF1 & 0.820 & 0.818 & 0.047 & 0.715 & 0.890 \\
\hline & PAF2 & 0.802 & 0.800 & 0.050 & 0.692 & 0.891 \\
\hline & PAF5 & 0.651 & 0.641 & 0.087 & 0.441 & 0.770 \\
\hline \multirow{4}{*}{$\begin{array}{l}\text { Personal Attitude to } \\
\text { the Environment } \\
\text { (PAE) }\end{array}$} & PAE1 & 0.804 & 0.804 & 0.036 & 0.725 & 0.863 \\
\hline & PAE2 & 0.832 & 0.829 & 0.034 & 0.755 & 0.885 \\
\hline & PAE3 & 0.892 & 0.890 & 0.020 & 0.848 & 0.921 \\
\hline & PAE4 & 0.804 & 0.799 & 0.042 & 0.702 & 0.867 \\
\hline \multirow{3}{*}{$\begin{array}{c}\text { Organizational } \\
\text { Attitude to Green IS } \\
\text { (OAGIS) }\end{array}$} & OAGIS1 & 0.893 & 0.891 & 0.018 & 0.851 & 0.924 \\
\hline & OAGIS2 & 0.866 & 0.862 & 0.028 & 0.800 & 0.909 \\
\hline & OAGIS 3 & 0.882 & 0.880 & 0.023 & 0.829 & 0.919 \\
\hline \multirow{3}{*}{$\begin{array}{l}\text { Pollution Prevention } \\
\qquad(\mathrm{PP})\end{array}$} & PP1 & 1.000 & 1.000 & 0.000 & 1.000 & 1.000 \\
\hline & PP2 & 0.890 & 0.889 & 0.022 & 0.839 & 0.924 \\
\hline & PP3 & 0.924 & 0.923 & 0.014 & 0.892 & 0.947 \\
\hline \multirow{4}{*}{$\begin{array}{l}\text { Product Stewardship } \\
\text { (PS) }\end{array}$} & PS1 & 0.812 & 0.809 & 0.048 & 0.709 & 0.882 \\
\hline & PS2 & 0.887 & 0.885 & 0.025 & 0.837 & 0.929 \\
\hline & PS3 & 0.930 & 0.928 & 0.020 & 0.880 & 0.961 \\
\hline & PS4 & 0.942 & 0.941 & 0.014 & 0.913 & 0.964 \\
\hline \multirow{4}{*}{$\begin{array}{l}\text { Sustainable } \\
\text { Development } \\
\text { (SD) }\end{array}$} & SD1 & 0.887 & 0.885 & 0.022 & 0.835 & 0.922 \\
\hline & SD2 & 0.771 & 0.774 & 0.033 & 0.707 & 0.831 \\
\hline & SD3 & 0.770 & 0.765 & 0.050 & 0.659 & 0.845 \\
\hline & SD4 & 0.764 & 0.758 & 0.051 & 0.628 & 0.841 \\
\hline \multirow{6}{*}{$\begin{array}{l}\text { Organizational } \\
\text { Benefits } \\
\text { (OB) }\end{array}$} & OB1 & 0.755 & 0.755 & 0.042 & 0.663 & 0.826 \\
\hline & OB2 & 0.818 & 0.816 & 0.051 & 0.707 & 0.901 \\
\hline & OB3 & 0.803 & 0.800 & 0.057 & 0.664 & 0.889 \\
\hline & OB4 & 0.734 & 0.728 & 0.062 & 0.585 & 0.831 \\
\hline & OB5 & 0.860 & 0.854 & 0.041 & 0.768 & 0.918 \\
\hline & OB6 & 0.916 & 0.916 & 0.015 & 0.887 & 0.944 \\
\hline
\end{tabular}

\section{References}

1. Melville, N.P. Information Systems Innovation for Environmental Sustainability. MIS Q. 2010, 34, 1-21. [CrossRef]

2. Watson, R.T.; Boudreau, M.-C.; Chen, A.J.; Huber, M. Green IS: Building Sustainable Business Practices. Inf. Syst. J. 2008, 76, 1-15.

3. Loeser, F. Green IT and Green IS: Definition of Constructs and Overview of Current Practices. In Proceedings of the Nineteenth Americas Conference on Information Systems, Chicago, IL, USA, 15-17 August 2013. 
4. Recker, J. Tutorial Green Information Systems. Presented at 22nd Americas Conference on Information Systems (AMCIS), San Diego, CA, USA, 11-14 August 2016.

5. Brooks, S.; Wang, X.; Sarker, S. Unpacking Green IS: A Review of the Existing Literature and Directions for the Future. In Green Business Process Management: Towards the Sustainable Enterprise; vom Brocke, J., Seidel, S., Recker, J., Eds.; Springer: Berlin/Heidelberg, Germany, 2012; pp. 15-37, ISBN 978-3-642-27488-6.

6. Deng, Q.; Ji, S. Organizational green IT adoption: Concept and evidence. Sustainability 2015, 7, 16737-16755. [CrossRef]

7. Muhammad, S.; Jusoh, Y.Y.A.H.; Din, J.; Nor, R.N.H. Green Information Systems Design Framework: A Systematic Literature Review. J. Theor. Appl. Inf. Technol. 2017, 95, 1338-1346.

8. Recker, J. Toward a design theory for green information systems. In Proceedings of the 2016 49th Hawaii International Conference on System Sciences (HICSS), Koloa, HI, USA, 5-8 January 2016; pp. 4474-4483.

9. Loeser, F.; Recker, J.; vom Brocke, J.; Molla, A.; Zarnekow, R. How IT executives create organizational benefits by translating environmental strategies into Green IS initiatives. Inf. Syst. J. 2017, 27, 503-553. [CrossRef]

10. Chen, A.J.; Watson, R.T.; Karahanna, E. Organizational Adoption of Green IS \& IT: An Institutional Perspective. In Proceedings of the ICIS 2009 Proceedings, Phoenix, AZ, USA, 15-18 December 2009; pp. 1-17.

11. Murugesan, S. Harnessing Green IT: Principles and Practices. IT Prof. 2008, 10, 24-33. [CrossRef]

12. Corbett, J. Unearthing the Value of Green IT. In Proceedings of the ICIS 2010 Proceedings, St. Louis, MO, USA, 12-15 December 2010; Volume 198.

13. El-Gayar, O.; Fritz, B.D. Environmental Management Information Systems (EMIS) for Sustainable Development: A Conceptual Overview. Commun. Assoc. Inf. Syst. 2006, 17, 34. [CrossRef]

14. Thambusamy, R.; Salam, A.F. Corporate Ecological Responsiveness, Environmental Ambidesterity and IT-Enabled Environmental Sustainability Strategy. In Proceedings of the ICIS 2010 Proceedings, Saint Louis, MO, USA, 12-15 December 2010; pp. 1-11.

15. Albino, V.; Balice, A.; Dangelico, R.M. Environmental strategies and green product development: An overview on sustainability-driven companies. Bus. Strateg. Environ. 2009, 18, 83-96. [CrossRef]

16. Bengtsson, F.; Ågerfalk, P.J. Information technology as a change actant in sustainability innovation: Insights from Uppsala. J. Strateg. Inf. Syst. 2011, 20, 96-112. [CrossRef]

17. Besson, P.; Rowe, F. Strategizing information systems-enabled organizational transformation: A transdisciplinary review and new directions. J. Strateg. Inf. Syst. 2012, 21, 103-124. [CrossRef]

18. Vom Brocke, J.; Seidel, S.; Recker, J. Green Business Process Management. Green Bus. Process Manag. 2012, 3-13.

19. OECD. Environmental Policy Toolkit for Greening SMEs in the EU Eastern Partnership Countries; OECD: Paris, France, 2015.

20. Muller, P.; Julius, J.; Herr, D.; Koch, L.; Peycheva, V.; McKiernan, S. Annual Report on European SMEs 2016/2017: Focus on Self Employment; European Commission: Luxembourg, Luxembourg, 2017; ISBN 9789279741265.

21. Gholami, R.; Sulaiman, A.B.; Ramayah, T.; Molla, A. Senior managers' perception on green information systems (IS) adoption and environmental performance: Results from a field survey. Inf. Manag. 2013, 50, 431-438. [CrossRef]

22. Bokolo, T. Green Information Systems Integration in Information Technology Based Organizations: An Academic Literature Review. J. Soft Comput. Decis. Support Syst. 2016, 3, 45-66.

23. Wang, X.; Schneider, C.; Valacich, J.S. Enhancing creativity in group collaboration: How performance targets and feedback shape perceptions and idea generation performance. Comput. Hum. Behav. 2015, 42, 187-195. [CrossRef]

24. Akman, I.; Mishra, A. Sector diversity in Green Information Technology practices: Technology Acceptance Model perspective. Comput. Hum. Behav. 2015, 49, 477-486. [CrossRef]

25. Hilty, L.M.; Aebischer, B. ICT for Sustainability: An Emerging Research Field. What is Sustainability? In ICT Innovations for Sustainability. Advances in Intelligent Systems and Computing; Springer: Cham, Switzerland, 2014; Volume 310.

26. Ishida, H. The effect of ICT development on economic growth and energy consumption in Japan. Telemat. Inform. 2014, 32, 79-88. [CrossRef]

27. Kogelman, C.-A. CEPIS Green ICT Survey-Examining Green ICT Awareness in Organisations: Initial Findings. Eur. J. Inform. Prof. 2011, 12, 6-10. 
28. Mishra, D.; Akman, I.; Mishra, A. Theory of Reasoned Action application for Green Information Technology acceptance. Comput. Hum. Behav. 2014, 36, 29-40. [CrossRef]

29. Bokolo, T.; Noraini, C.P. A Framework for Adoption and Implementation of Green IT/IS Practice in IT Governance. In Proceedings of the Third International Conference on Green Computing, Technology and Innovation, Selangor, Malaysia, 8-10 December 2015; pp. 38-48.

30. Esfahani, M.D.; Rahman, A.A.; Zakaria, N.H. The Status Quo and the Prospect of Green IT and Green IS: A Systematic Literature Review. J. Soft Comput. Decis. Support Syst. 2015, 2, 18-34.

31. Jenkin, T.A.; Webster, J.; McShane, L. An agenda for 'Green' information technology and systems research. Inf. Organ. 2011, 21, 17-40. [CrossRef]

32. Zheng, D. The Adoption of Green Information Technology and Information Systems: An evidence from Corporate Social Responsibility. In Proceedings of the PACIS 2014 Proceeding, Chengdu, China, 24-28 June 2014; Volume 237.

33. Esfahani, M.D.; Shahbazi, H.; Nilashi, M. Moderating Effects of Demographics on Green Information System Adoption. Int. J. Innov. Technol. Manag. 2018, 16, 1950008. [CrossRef]

34. Meacham, J.; Toms, L.; Green, K.W.; Bhadauria, V.S. Impact of information sharing and green information systems. Manag. Res. Rev. 2013, 36, 478-494. [CrossRef]

35. Pernici, B.; Ardagna, D.; Cappiello, C. Business Process Design: Towards Service- Based Green Information Systems. Inf. Syst. J. 2008, 280, 195-203.

36. Raisinghani, M.S.; Idemudia, E.C. Green Information Systems for Sustainability. In Handbook of Research on Waste Management Techniques for Sustainability; Akkucukm, U., Ed.; IGI Global: Hershey, PA, USA, 2016; pp. 212-226.

37. Wati, Y.; Koo, C. Toward Green IS Adoption Behaviors: A Self-Determination Perspective. In Proceedings of the 2012 45th Hawaii International Conference on System Sciences, Maui, HI, USA, 4-7 January 2012; pp. 1207-1216.

38. Dalvi-Esfahani, M.; Rahman, A.A. An integrative framework to understand the influence of morality on green is adoption: A theoretical perspective. J. Theor. Appl. Inf. Technol. 2016, 88, 337-349.

39. Asadi, S.; Hussin, A.R.C.; Dahlan, H.M.; Yadegaridehkordi, E. Theoretical model for Green Information Technology adoption. ARPN J. Eng. Appl. Sci. 2015, 10, 17720-17729.

40. Wang, X.; Brooks, S.; Sarker, S. A review of green is research and directions for future studies. Commun. Assoc. Inf. Syst. 2015, 37, 395-429. [CrossRef]

41. Loock, C.; Staake, T.; Thiesse, F. Motivating Energy-Efficient Behavrior with Green IS: An Investigation of Goal Setting and the Role of Defaults. MIS Q. 2013, 37, 1313-1332. [CrossRef]

42. Chen, A.J.; Watson, R.T.; Boudreau, M.C.; Karahanna, E. An institutional perspective on the adoption of green IS \& IT. Australas. J. Inf. Syst. 2011, 17, 23-45.

43. Kranz, J.; Picot, A. Why Are Consumers Going Green? the Role of Environmental Concerns in Private Green-Is Adoption. In Proceedings of the 19th European Conference on Information Systems, ECIS 2011, Helsinki, Finland, 9-11 June 2011.

44. Ryoo, S.Y.; Koo, C. Green practices-IS alignment and environmental performance: The mediating effects of coordination. Inf. Syst. Front. 2013, 15, 799-814. [CrossRef]

45. Nedbal, D.; Wetzlinger, W.; Auinger, A.; Wagner, G. Sustainable IS initialization through outsourcing: A theory-based approach. In Proceedings of the 17th Americas Conference on Information Systems, AMCIS 2011, Detroit, MI, USA, 4-8 August 2011; Volume 3, pp. 2282-2291.

46. Lin, Y.-L.; Yang, Y.S.O.; Hsu, C. Building Legitimacy for Green IS Innovations in Taiwan. In Proceedings of the 17th Pacific Asia Conference on Information Systems, PACIS 2013, Jeju Island, Korea, 18-22 June 2013; pp. 1-7.

47. Lei, C.F.; Ngai, E.W.T. Green IS Assimilation: A Theoretical Framework and Research Agenda. In Proceedings of the AMCIS 2012, Seattle, WA, USA, 9-12 August 2012.

48. Malhotra, A.; Melville, N.P.; Watson, R.T. Spurring Impactful Research on Information Systems and Environmental Sustainability. MIS Q. 2013, 37, 1265-1274. [CrossRef]

49. Hernandez-Pardo, R.J.; Bhamra, T.; Bhamra, R. Exploring SME perceptions of sustainable product service systems. IEEE Trans. Eng. Manag. 2013, 60, 483-495. [CrossRef]

50. Kerr, I.R. Leadership strategies for sustainable SME operation. Bus. Strateg. Environ. 2006, 15, 30-39. [CrossRef] 
51. Verdolini, E.; Bak, C.; Ruet, J.; Venkatachalam, A. Innovative Green-technology SMEs as an Opportunity to Promote Financial de-risking. Economics 2018, 12, 1-12. [CrossRef]

52. Álvarez Jaramillo, J.; Zartha Sossa, J.W.; Orozco Mendoza, G.L. Barriers to sustainability for small and medium enterprises in the framework of sustainable development-Literature review. Bus. Strateg. Environ. 2018, 1-13.

53. Cuerva, M.C.; Triguero-Cano, Á.; Córcoles, D. Drivers of green and non-green innovation: Empirical evidence in Low-Tech SMEs. J. Clean. Prod. 2014, 68, 104-113. [CrossRef]

54. Pinget, A.; Bocquet, R.; Mothe, C. Barriers to Environmental Innovation in SMEs: Empirical Evidence from French Firms. M@n@gement 2015, 18, 132. [CrossRef]

55. Cecere, G.; Mazzanti, M. Green Jobs, Innovation and Environmentally Oriented Strategies in European SMEs; Sustainability Environmental Economics and Dynamics Studies: Ferrara, Italy, 2017.

56. Moorthy, M.K.; Yacob, P.; Chelliah, M.K.; Arokiasamy, L. Drivers for Malaysian SMEs to Go Green. Int. J. Acad. Res. Bus. Soc. Sci. 2012, 2, 74-86.

57. Musa, M.H.; Mohamad, M.N. Importance of Green Innovation in Malaysian SMEs: Advantages and Future Research. Int. Acad. J. Bus. Manag. 2018, 5, 64-73.

58. Yacob, P.; Moorthy, M.K. Green Practices: Perception of Malaysian SME Owners/Managers. Int. J. Acad. Res. Econ. Manag. Sci. 2012, 1, 103-111.

59. Kraus, S.; Burtscher, J.; Niemand, T.; Roig-tierno, N.; Syrjä, P. Configurational Paths to Social Performance in SMEs: The Interplay of Innovation, Sustainability, Resources and Achievement Motivation. Sustainability 2017, 9, 1828. [CrossRef]

60. Kraus, S.; Burtscher, J.; Vallaster, C.; Angerer, M. Sustainable Entrepreneurship Orientation: A Reflection on Status-Quo Research on Factors Facilitating Responsible Managerial Practices. Sustainability 2018, 10, 444. [CrossRef]

61. Buchalcevova, A.; Gala, L. Green ICT Adoption Survey Focused on ICT Lifecycle from the Consumer's Perspective (SMEs). J. Compet. 2012, 4, 109-122. [CrossRef]

62. Buchalcevova, A.; Gala, L. Green ICT drivers and inhibitors perceived by the Czech SMEs. J. Syst. Integr. 2013, 4, 43-49.

63. Hernandez, A.A. Exploring the Factors to Green IT Adoption in SMEs in the Philippines. In Proceedings of the IST-Africa 2014 Conference Proceedings, Vienna, Austria, 4-6 December 2018; Volume 20, pp. 49-66.

64. Muafi, M. Green IT empowerment, social capital, creativity and innovation: A case study of creative city, Bantul, Yogyakarta, Indonesia. J. Ind. Eng. Manag. 2015, 8, 719-737. [CrossRef]

65. Foogooa, R.; Dookhitram, K. A self green ICT maturity assessment tool for SMEs. In Proceedings of the 2014 IST-Africa Conference Proceedings, Le Meridien Ile Maurice, Mauritius, 7-9 May 2014.

66. Mithas, S.; Khuntia, J.; Roy, P.K. Green Information Technology, Energy Efficiency, and Profits: Evidence from an Emerging Economy Green Information Technology, Energy Efficiency, and Profits: Evidence from an Emerging Economy. In Proceedings of the 31st International Conference on Information Systems, St. Louis, MO, USA, 12-15 December 2010.

67. Radu, L. Determinants of Green ICT Adoption in Organizations: A Theoretical Perspective. Sustainability 2016, 8, 731. [CrossRef]

68. Yang, Z.; Sun, J.; Zhang, Y. Employees' Collaborative Use of Green Information Systems. In Proceedings of the 50th Hawaii International Conference on System Sciences, Waikoloa, Hi, USA, 4-7 January 2017.

69. Ijab, M.T.; Molla, A.; Cooper, V. Green Information Systems (Green IS) Practice in Organisation: Tracing its Emergence and Recurrent Use. In Proceedings of the AMCIS 2012 Proceedings, Seattle, WA, USA, 9-12 August 2012; p. 6.

70. DiMaggio, P.; Powell, W. The iron cage revisited: Institutional isomorphism and collective rationality in organization fields. Am. Sociol. Rev. 1983, 48, 147-160. [CrossRef]

71. Chen, A.J.W.; Boudreau, M.; Watson, R.T. Information systems and ecological sustainability. J. Syst. Inf. Technol. 2008, 10, 186-201. [CrossRef]

72. Mizruchi, M.S.; Fein, L.C. The Social Construction of Organizational Knowledge: A Study of the Uses of Coercive, Mimetic, and Normative Isomorphism. Adm. Sci. Q. 1999, 44, 653-683. [CrossRef]

73. Jamil, C.Z.M.; Mohamed, A.A.; Muhammad, F.; Ali, A. Environmental management accounting practices in small medium manufacturing firms. Procedia Soc. Behav. Sci. 2015, 172, 619-626. [CrossRef] 
74. Dumont, J.; Franjeska-Nicole, B.C. Learning About the Environment: The Role of Information Technology in Shaping Attitudes and Developing Solutions. SynEnergy Forum; University of Indianapolis: Indianapolis, IN, USA, 2008.

75. Eurostat. Statistical Classification of Economic Activities in the European Community; NACE Rev. 2; Eurostat: Luxembourg, Luxembourg, 2008; ISBN 9789279047411.

76. Chin, W.W. How to Write Up and Report PLS Analyses. In Handbook on Partial Least Squares; Espozito Vinci, V., Chin, W.W., Henseler, J., Wang, H., Eds.; Springer: Berlin/Heidelberg, Germany, 2010; pp. 655-689, ISBN 978-3-540-32825-4.

77. Sanchez, G. PLS Path Modeling with R; Trowchez Editions: Berkeley, CA, USA, 2013.

78. Henseler, J.; Sarstedt, M. Goodness-of-fit indices for partial least squares path modeling. Comput. Stat. 2013, 28, 565-580. [CrossRef]

79. Ravand, H.; Baghaei, P. Partial Least Squares Structural Equation Modeling with R. Pract. Assess. Res. Eval. 2016, 21, 1-16.

80. Fornell, C.; Larcker, D.F. Evaluating Structural Equation Models with Unobservable Variables and Measurement Error. J. Mark. Res. 1981, 18, 39-50. [CrossRef]

81. Escobar-Rodriguez, T.; Monge-Lozano, P. The acceptance of Moodle technology by business administration students. Comput. Educ. 2012, 58, 1085-1093. [CrossRef]

82. Chin, W.W. The Partial Least Squares Approach to Structural Equation Modeling. In Modern Methods for Business Research; Marcoulides, G.A., Ed.; Lawrence Erlbaum Associates: Mahwah, NJ, USA, 1998.

83. Hair, J.F.; Tomas, G.; Hult, M.; Ringle, C.M.; Sarstedt, M. A primer on Partial Least Squares Structural Equation Modeling (PLS-SEM); SAGE Publications: London, UK, 2014.

84. Roldán, J.L.; Sánchez-Franco, M.J. Variance-Based Structural Equation Modeling: Guidelines for Using Partial Least Squares in Information System Research. In Research Methodologies, Innovations and Philosophies in Software Systems Engineering and Information Systems; Mora, M., Gelman, O., Steenkamp, A.L., Raisinghani, M., Eds.; IGI Global: Hershey, PA, USA, 2014; pp. 193-221, ISBN 9781466601796.

85. Jansson, J.; Nilsson, J.; Modig, F.; Vall, G.H. Commitment to Sustainability in Small and Medium-Sized Enterprises: The Influence of Strategic Orientations and Management Values. Bus. Strateg. Environ. 2017, 26, 69-83. [CrossRef]

86. Nowduri, S.; Al-dossary, S. Management Information Systems and Its Support to Sustainable Small and Medium Enterprises. Int. J. Bus. Manag. 2012, 7, 125-131. [CrossRef]

87. Butler, T. Towards a Practice-Oriented Green IS Framework. In Proceedings of the 19th European Conference on Information Systems, ECIS 2011, Helsinki, Finland, 9-11 June 2011; pp. 1-13.

88. Bose, R.; Luo, X. Integrative framework for assessing firms' potential to undertake Green IT initiatives via virtualization-A theoretical perspective. J. Strateg. Inf. Syst. 2011, 20, 38-54. [CrossRef]

89. Engert, S.; Rauter, R.; Baumgartner, R.J. Exploring the integration of corporate sustainability into strategic management: A literature review. J. Clean. Prod. 2016, 112, 2833-2850. [CrossRef]

90. OECD. Issues Paper 3: SMEs and Green Growth: Promoting Sustainable Manufacturing and Eco-Innovation in Small Firms; OECD: Paris, France, 2010.

91. SOM Steering Committee on Economic and Technical Cooperation. The Role of Business Incubators in Developing Green Technology-Based SMEs; SOM Steering Committee on Economic and Technical Cooperation: Singapore, 2011.

92. Bohas, A.; Poussing, N. An empirical exploration of the role of strategic and responsive corporate social responsibility in the adoption of different Green IT strategies. J. Clean. Prod. 2016, 122, 240-251. [CrossRef]

93. Forsman, H. Environmental innovations as a source of competitive advantage or vice versa? Bus. Strateg. Environ. 2013, 22, 306-320. [CrossRef]

94. Surroca, J.; Tribo, J.A.; Waddock, S. Corporate responsibility and financial performance: The role of intangible resources. Strateg. Manag. J. 2010, 31, 463-490. [CrossRef]

95. Graves, L.M.; Sarkis, J. The role of employees' leadership perceptions, values, and motivation in employees' provenvironmental behaviors. J. Clean. Prod. 2018, 196, 576-587. [CrossRef]

(C) 2019 by the authors. Licensee MDPI, Basel, Switzerland. This article is an open access article distributed under the terms and conditions of the Creative Commons Attribution (CC BY) license (http://creativecommons.org/licenses/by/4.0/). 